\title{
A Survey of Radiation Exposure Techniques Factors Used for Common Diagnostics X- Ray Examinations in Akwa Ibom State, Nigeria
}

\author{
Essien Imeh Edet ${ }^{1,}$, , Inyang Samuel Okon ${ }^{2}$ \\ ${ }^{1}$ Department of Physics, Faculty of Science, University of Uyo, Uyo, Akwa Ibom State, Nigeria \\ ${ }^{2}$ Department of Physics, Faculty of Science, University of Calabar, Calabar, Cross River State, Nigeria
}

Email address:

imeessien27@yahoo.com (Essien I. E.)

\section{To cite this article:}

Essien Imeh Edet, Inyang Samuel Okon. A Survey of Radiation Exposure Techniques Factors Used for Common Diagnostics X- Ray Examinations in Akwa Ibom State, Nigeria. International Journal of Medical Imaging. Vol. 3, No. 4, 2015, pp. 69-74.

doi: $10.11648 /$ j.ijmi.20150304.11

\begin{abstract}
The dose of radiation emitted by an X-ray source and delivered on a target depends on the source tube peak potential $(\mathrm{kVp})$, the current time (mAs) and the source to film distance (FFD). There could be an harmful health effect on the patient if these exposure technique factors are not appropriately selected by the operators of these sources. Therefore the aim of this study is to survey the choice of these technique factors in X-ray departments in Akwa Ibom State, Nigeria, while undertaking some common diagnostic X-ray examinations. The common and mostly requested examinations considered were, Chest (PA), Skull (AP), Pelvis (AP) and Abdomen (AP). A total of 48 personnel, 952 adult volunteers in X-ray departments in nine Hospitals took part in the survey. The adults were age between $20-75$ yrs and body weight $70 \pm 13 \mathrm{~kg}$. Variations in the technique factors selected for the different examination were observed when compared with the values in CEC guidelines on quality criteria. The mean tube potential of $125 \mathrm{kVp}$ selected for chest examination in this study is low compared to $180 \mathrm{kVp}$ in the CEC. The mean mAs varies while some departments employed constant mAs for all examination and all patients not taking into account the body thickness of the patient. In skull and pelvis examination, some departments used lower $\mathrm{kVps}$ while some selected tube potentials within the CEC range of 70-85 kVp and 75-90 kVp respectively the mean FFD (162.0 cm) for chest in this study was within the CEC recommended value of $180.0 \mathrm{~cm}$ while low values of FFD were used in other examinations. Human and equipment factors were identified as possible reasons for the variations. The replacement of X-ray machines of more than 10 years, development of adequate and functional quality assurance programme for the facilities and retraining of the personnel are recommended as a panacea to minimize these variations.
\end{abstract}

Keywords: Technique Factors, Diagnostic X-ray, Health Effect, Chest, Abdomen, Skull, Pelvic

\section{Introduction}

The application of X-ray in health care services for the diagnosis and management of diseases has globally increased rapidly since the discovery of X-rays. Diagnostic imaging has been reported to increase at the rate of $5 \%$ per year with a worldwide annual per caput dose of $0.4 \mathrm{mSv}$ (Osibote and Azevedo, 2008). This indirectly ionising radiation though useful in clinical applications could be harmful if not properly applied, utilized and managed or the patient is not properly protected from it when undergoing medical examination (Vano, 2003 and Miralbell et al, 2000) also its effect on the eye of the patient has also been reported (Vano et al, 1998). In the majority of circumstances where human beings interact with radiations from any sources there is bound to be an effect no matter how low the dose might be. However cancer that is said to be the common effect arising from ionising radiation can also be as a result of interacting with radiation from other sources and medical exposure accounts for the largest source of radiation irradiating man.

The United Nation Scientific Committee on the Effects of Atomic Radiation (UNSCEAR) put a worldwide annual diagnostic exposure at approximately 3.6 billion, out of which exposure for clinical purposes accounts for 3.1 (78\%) of the diagnostic exposure and 0.5 ( $21 \%$ ) for dental X-ray examinations (UNSCEAR, 2008). The potential hazards of radiation could be minimized of the facilities owners adopt programs that could enhance the quality and quantity of the 
X-rays used during medical examinations.

For the safety of the patients undergoing X-ray examinations, it is required that, the use of ionizing radiation in diagnostic radiology should be justified and optimized. The optimization and justification procedure is to maintain the dose of exposure as low as reasonably achievable, taking into account economic, social and environmental factors (NNRA, 2006). Optimization in diagnostic radiology is achieved where standard equipment are used, proper and standardized technique factors are selected from the machine, patient doses are monitored regularly and adequate quality control (QC) program is put in place in the facility. (IAEA,1996). The QC program comprises of regular testing of the equipment to ensure its optimal performance (AAPM 2002), also to ensure that a high quality diagnostic image is produced from minimum dose on both pediatrics and adults patients. In addition, QC test include, visual inspection of the equipment, environmental monitoring of radiation and assessment of exposure parameters (Aghahadi et al, 2006). Patient dose during medical examination could be optimized when appropriate technique factors are applied and consequently, good image quality with maximum diagnostic efficiency is obtained.

The Commission of European Communities (CEC) has issued guidelines on the choice of good techniques for a range of common X-rays examinations which if adhered to could lead to the optimization of dose, good quality image and patients protection ( CEC, 1996, Johnson and Brennan, 2000). The radiation exposure technique factors of concern in this study are those of geometric concern such as focal to film distance (FFD), peak voltage $(\mathrm{kVp})$ and tube current- time product (mAs). The equipment technical parameters such as, filtration (HVL) and age of the machine are also considered. Unfortunately, the machines in these facilities do not have automatic exposure control (AEC), hence was not considered in this study. In addition, the common X-ray examination considered were, chest posterior- anterior (PA), skull anterior posterior (AP), pelvis (AP), and abdomen (AP).

\section{The Nigerian Nuclear Regulatory Authority}

In Nigeria, the use of ionizing radiation is regulated by the Nigerian Nuclear Regulatory Authority (NNRA) established by the nuclear safety and radiation protection act 19 of 1995 . The NNRA is empowered to categorize and license all activities involving the application ionising radiation and equipment emitting ionising radiation. Others powers of NNRA include, monitoring of the production, possession, processing, manufacturing, purchasing, sale, importation, transfer, storage and disposal of radioactive substances (NNRA, 2003). Importantly, to ensure effective monitoring of facilities by NNRA and to enhance safety of patients presenting for clinical use of X-rays, it is expected that all diagnostic radiology facilities in Nigeria be registered with NNRA.

\section{Aim and Objective}

The aim of this study is to survey the radiation exposure technique factors applied in X-ray departments in Akwa Ibom State, Nigeria for the four common X-ray examinations and examine its compliance with the Commission of European Communities (CEC) criteria.

\section{Materials and Method}

The X-ray departments located in Akwa Ibom State, South South Nigeria were selected for this study. The selection for inclusion in this study was based on the frequency of $\mathrm{X}$ - ray examinations carried out in these facilities where we obtained enough data for analysis. These facilities were tertiary, secondary and private facilities. Tertiary facilities (TF), are those in teaching hospitals and specialist hospitals while secondary facilities (SF) are those in general hospital and private facilities are in stand alone departments. The need to include all types of facilities was to have a good geographical spread of the facilities in parts of the State.

The radiation exposure techniques factors considered here were those applied for adult patients of age between $20-75$ years, body weight $70 \pm 13 \mathrm{~kg}$ (IAEA, 2007) and body thickness (BT) range of $6.0 \mathrm{kgm}^{-1}-9.8 \mathrm{kgm}^{-1}$ where body thickness was calculated from the mass and height of the patients, using the equation below (Nyathi, et al 2009, Milatovic et al; 2011)

$$
B T=2\left(\frac{W}{\pi \times h}\right)^{\frac{1}{2}}
$$

Where $W$ is the weight of the patient and $h$ the height of the patient.

Nine hospitals took part in the study comprising of one (11\%) $\mathrm{TF}$, four (44\%) SF and four (44\%) PF. The tertiary facility is the one in the only teaching hospital in the State which has more radiographers and radiologists than others and a training institution; hence their operation is expected to be better optimized.

The radiation exposure techniques factors used by the radiographers were obtained using three predesigned forms. The patient information form recorded patient details such as age, weight and height while the technique form recorded details such as $\mathrm{kVp}$. FFD and $\mathrm{mAs}$ and the third form recorded details about the $\mathrm{X}$ - ray machine such as age, filtration and year of installation. To ensure that dependable data were obtained, the forms were handed over to the most senior radiographer who in turn supervised the completion of the form by the radiographer on duty.

\section{Results and Discussion}

A total of 952 patients whose consent we obtained orally were examined during the period of study for four common $\mathrm{X}$-ray examinations, 48 personnel took part in the nine facilities. Data obtained from the forms are analyzed and 
presented as mean in tables $1-5$. Table 1.0 Equipment parameters and comparison with CEC criteria, indicating the age and half value layer (HVL) of the equipment while tables $2.0-5.0$ are the mean values of radiographic technique factors for each of the examination.

Table 1.0. Equipment parameters and comparison with CEC criteria

\begin{tabular}{lll}
\hline Hospital No & Age (Yrs) & Filtration \\
\hline 1 & 17 & 2.9 \\
2 & $*$ & 2.9 \\
3 & 34 & 2.5 \\
4 & 5 & 1.5 \\
5 & 10 & 2.0 \\
6 & 5 & 2.0 \\
7 & 14 & 2.0 \\
8 & 5 & 1.5 \\
9 & 9 & 2.0 \\
CEC & 10 & $\geq 3.0$ \\
\hline
\end{tabular}

*The year of installation was not provided.

The result of the equipment specification is shown in table 1.0 and the summary shows the ages of the machines and their inherent filtration. X-ray machine in hospital 3 is the oldest, 34 years while the machines in hospitals 4,6 , and 8 are 5 years old respectively.

The mean of the radiation exposure techniques factors used in chest (PA) examinations is summarized in table 2.0

Table 2.0. Mean value of radiation exposure technique factors used in the hospital for chest (PA)

\begin{tabular}{llll}
\hline Hospital No & $\mathbf{k V p}(\mathbf{V})$ & $\mathbf{m A s}$ & FFD $(\mathbf{c m})$ \\
\hline 1 & 74.0 & 4.8 & 150.0 \\
2 & 61.2 & 17.6 & 173.6 \\
3 & 46.8 & 8.8 & 150.0 \\
4 & 62.2 & 37.3 & 175.7 \\
5 & 60.0 & 43.3 & 180.0 \\
6 & 70.1 & 25.0 & 160.0 \\
7 & 64.0 & 41.0 & 158.0 \\
-8 & 70.0 & 18.0 & 150.0 \\
9 & 75.0 & 13.0 & 150.0 \\
CEC & 125.0 & - & 180.0 \\
\hline
\end{tabular}

Table 3.0. Mean values of radiographic technique factors used in the hospital for skull (AP)

\begin{tabular}{llll}
\hline Hospital No & $\mathbf{k V p}(\mathbf{V})$ & $\mathbf{m A s}$ & FFD \\
\hline 1 & $-* *$ & - & - \\
2 & 75.0 & 24.0 & 100.0 \\
3 & 70.0 & 20.0 & 104.0 \\
4 & 63.0 & 54.0 & 107.0 \\
5 & 80.0 & 90 & 100.0 \\
6 & $-* *$ & - & - \\
7 & 41.2 & 29.0 & 113.0 \\
8 & 73.0 & 17.0 & 105.0 \\
9 & 90.0 & 45.0 & 103.0 \\
CEC & 65.0 & 150.0 & 115.0 \\
\hline
\end{tabular}

** The number of results obtained from these facilities for the examination was not large enough to be included in the study
Table 4.0. Mean values of radiation exposure techniques factors for Pelvis examination.

\begin{tabular}{llll}
\hline Hospital No. & KVp & mAs & FFD \\
\hline 1 & 70.0 & 4.8 & 100.0 \\
2 & $* *$ & - & - \\
3 & 70.0 & 5.8 & 104.0 \\
4 & 67.0 & 50.0 & \\
5 & 60.0 & 7.0 & - \\
6 & $* *$ & & \\
7 & 53.0 & 25.0 & 168.0 \\
8 & 80.0 & 25.0 & 103.0 \\
9 & 75.0 & 150.0 & 90.0 \\
CEC & $90.0 * * *$ & - & 115.0 \\
\hline
\end{tabular}

*** Maximum value $\mathrm{kVp}$ is used

Table 5.0. Mean values of radiation exposure techniques factors for Abdomen examination.

\begin{tabular}{ll|ll}
\hline Hospital No. & KVp & mAs & FFD \\
\hline 1 & $* *$ & $* *$ & $* *$ \\
2 & $* *$ & $* *$ & $* *$ \\
3 & 74.0 & 29.0 & 103.0 \\
4 & 71.0 & 50.0 & 110.0 \\
5 & 88.0 & 141.0 & 100.0 \\
6 & 55.0 & 25.0 & 103.0 \\
7 & 55.0 & 34.0 & 156.0 \\
8 & 73.0 & 28.0 & 105.0 \\
9 & 75.0 & 33.0 & 90.0 \\
CEC & 90.0 & - & 115.0 \\
\hline
\end{tabular}

Example of good radiation exposure technique factors that could enhance better diagnostic radiographic images are enshrine in the European guidelines on image quality criteria, (CEC, 1996) limitations of facilities in our third world countries notwithstanding. However, it is necessary to compare the technique factors used in the facilities study with the European criteria. The result of the equipment specifications in this study and its comparison with the CEC recommendation is summarized in table 6.0.

The result in table 6.0 shows that the total half value layer (HVL) in all the facilities were below the CEC recommended value even though facilities 1 and 2 had HVL 0.1 less than the CEC values. In a standard medical $\mathrm{x}$-ray tube, it is expected that the filters incorporated in the machine should be at least $3.0 \mathrm{mmAl}$ thick to ensure the safety of the patient and optimization of dose. This is necessary because insufficient total filtration of the X-ray beam is being reported to increase the entrance surface dose (ESD) (Martin 2006).

For the age of the machine investigated shows that $44 \%$ of the machines under study were above the recommended 10 years life, this could affect the performance level of the machine due to tear and wear and the image quality affected the expertise of the operators notwithstanding. 
Table 6.0. Comparison of equipment specification in this study with CEC recommendation

\begin{tabular}{llllll|l}
\hline \multirow{2}{*}{ Examination } & \multirow{2}{*}{ No. of facilities studied } & \multicolumn{2}{l}{ Age (Yrs) } & \multicolumn{2}{l}{ HVL (mmAl) } \\
\cline { 3 - 7 } & & CEC & No. of facilities achieving compliance & CEC & No. of facilities achieving compliance \\
\hline Chest (PA) & 9 & $\leq 10$ & 5 & $\geq 3.0$ & Nil \\
Skull (AP) & 8 & $\leq 10$ & 4 & $\geq 3.0$ & Nil \\
Pelvis (AP) & 6 & $\leq 10$ & 3 & $\geq 3.0$ & Nil \\
Abdomen (AP) & 7 & $\leq 10$ & 5 & $\geq 3.0$ & Nil \\
\hline
\end{tabular}

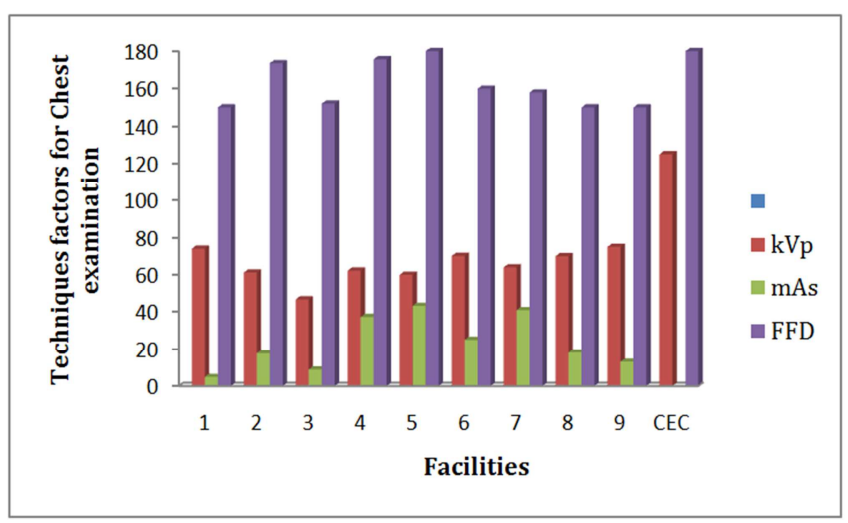

Fig. 1.0. Technique factors for chest examination and CEC recommendations

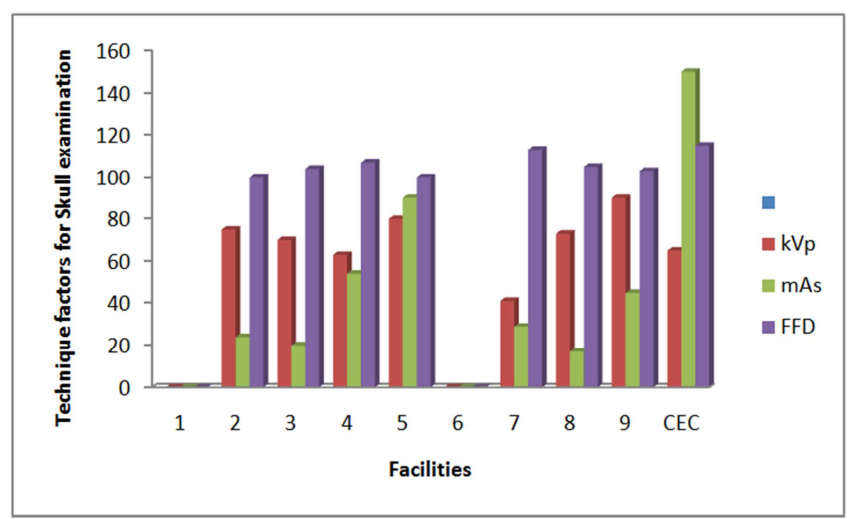

Fig. 2.0. Technique factors for skull examination and CEC recommendation

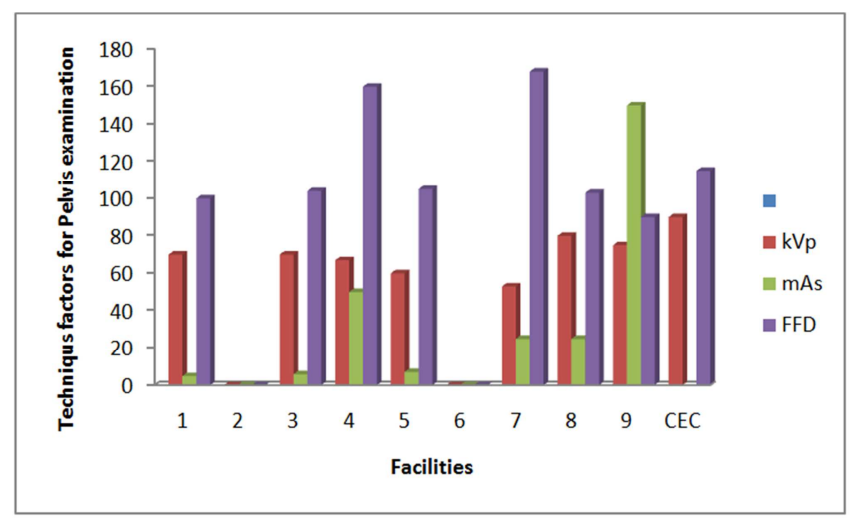

Fig. 3.0. Technique factors for Pelvis examination and CEC recommendation

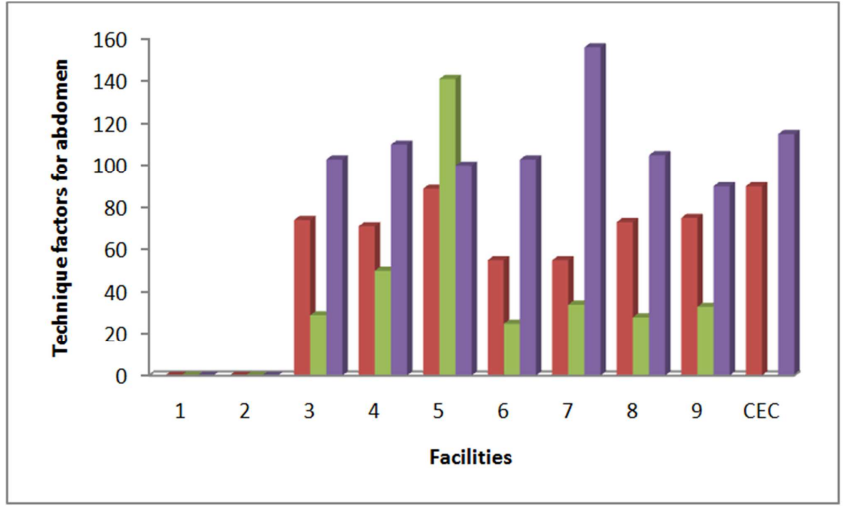

Fig. 4.0. Technique factors for abdomen examination and CEC recommendations

Generally, the applied technique factors in all the facilities study for all the examination were either too low or too high for same examinations as compared with the CEC recommendations (Figs. $1.0-4.0$ )

In chest posterior - anterior (PA) examination, the mean $\mathrm{kVp}$ applied by all the facilities investigated was too low compared to the $\mathrm{CEC}$ value of $125 \mathrm{kVp}$. The percentage deviation between the CEC value and the selected values by facilities under study shows hospital 3 with the highest percentage deviation of $63.0 \%$ while hospital 9 has the lowest percentage deviation of $40 \%$. The observed low deviation in hospital 9 is not unexpected as it is a training institution (Teaching hospital) with more qualified diagnostic radiology personnel while hospital 3 is a privately owned standalone facility.

It is noticed that, there is wide variation in the selected technique factors for same examination in the different hospitals.

Comparison of the mean tube loadings (mAs) between facilities shows wide variations where hospital 4 selected a mean $\mathrm{mAs}$ of $43.3 \mathrm{mAs}$ in chest examination, the highest in all the facilities investigated, while the lowest mean mAs of $4.8 \mathrm{mAs}$ for chest examination was recorded by hospital 1 . Hospital 1 is a University Medical Centre which provide services for the students and staff, also has more expert hands. Again some facilities employed constant value of $\mathrm{mAs}$ for same examination, irrespective of variation in the body mass index (BMI) and body thickness (BT) of the patients. The use of constant $\mathrm{mAs}$ for all patient is not good radiographic practice because patient with small BMI or BI could be 
overexposed while patient BMI or BI could be underexposed, also the body organ dose (BOD) and effective dose (ED) could be underestimated because the quantity of radiation absorbed by the body depends on the applied mAs (Huda, 1996). In addition, the use of constant $\mathrm{kVp}$ for all the patients is not a good practice as the penetrative power of the radiation largely depends on the applied voltage $\mathrm{kVp}$.

It could also be observed in Figs 2.0 and 3.0 that some facilities selected $\mathrm{kVp}$ value within the CEC guidelines while some facilities selected values lower than the recommended $\mathrm{kVp}$.

Comparison of the FFD values in this study with CEC values indicates that the mean FFD of $162.0 \mathrm{~cm}$ selected for chest examination by all the facilities was within the CEC range while very low FFDs were used for other examinations. Further investigation, shows some facilities selected FFD of $104.0 \mathrm{~cm}$ for abdomen, skull and pelvis examination which is $11.0 \mathrm{~cm}$ less than the minimum CEC recommendation.

However, the variation in the choice of radiation techniques with the $\mathrm{CEC}$ value is not peculiar only to facilities investigated. For example, in tube loading (mAs) settings, for pelvis examination, the range selected in this study was within the values of $\mathrm{mAs}$ reported in UK (Akinlade, et al., 2012). Comparing the mAs selected for skull examination in this study to other studies elsewhere shows variations in values selected for same examination (Bouzarjomehri, 2004).

It is worthy to note that the recommendation of these standard technique factors is to reduce patient dose and enhance safety of the patients. This is because there is a direct relationship between $\mathrm{kVp}, \mathrm{mAs}, \mathrm{FFD}$ and entrance surface dose (ESD), where ESD is directly proportional to $\mathrm{kVp}$ and mAs and inversely proportional FFD (IAEA 2004). Therefore it is a good practice in diagnostic radiology to use high $\mathrm{kVp}$ and low $\mathrm{mAs}$ for the optimization of patient dose.

A lot of factors might contribute to the variations in the choice of the technique factors by the different facilities. It could be human factors where the operators of machine select the factors according to their observed patient size. This manual choice of these techniques could lead to noncorrelation between patient parameters and technique factors hence it is suggested that, the use of automatic exposure control (AEC) system could help overcome this challenge (Olowookere, et al 2011). Unfortunately, none of the facilities investigated had AEC. Secondly it could be due equipment limitations as some of the facilities are too old, wear and tear with long period of operation (Brennan and Johnson, 2002). Again the observed variation in CEC value and values in this study could also be due the difference in procedure, type and model of equipment used in the CEC study and again the level of professionalism of the personnel.

\section{Conclusion}

The result of this study showed variations between the operational techniques factors in the facilities investigation and the CEC guidelines. These variations have been seen to be caused by both human and equipment limitations. Although the CEC recommendations are not a fast and rule, it could be seen as a maximum standard for optimization of diagnostic radiology procedures.

\section{References}

[1] AAPM (2002). Quality control in diagnostic radiology. American Association of Physicist in Medicine Report (74), Madison, Medical Physics Publishing

[2] Aghahadi, B., Zhang, Z, Zareh, S. Sarker S. \& Tayebi P. S (2006). Impact of quality control on radiation doses on patients undergoing abdomen $\mathrm{x}$-ray examination in ten hospitals, Iran Journal of Radiation Research. 3 (4) 177-182.

[3] Akinlade, B. I, F. Idowu, P. Okunde, and Akintude, A. (2012). Survey of dose area product received by patients undergoing common radiological examinations in four centres in Nigeria. Journal of Applied Clinical Medical Physics 13 (4), 15-1

[4] Bouzarjomehri, J (2004). Patient dose in routine X-ray examinations in Yazd State, Iran Journal of radiation Research. $1(4), 199-204$

[5] CEC, (1996). European guidelines on quality criteria for diagnostic radiographic images in pediatrics', Commission of European Communities

[6] Huda, W and Gkanatsios, M.A (1997). Effective dose and energy imparted in diagnostic radiology, Medical Physics, 24(8), 1311-1316

[7] IAEA (1996).International basic safety standards for protection against ionising radiation and for safety of radiation sources International Atomic Energy Agency, safety series no 115, Vienna, Austria

[8] IAEA (2004). Optimization of radiological protection of patients undergoing radiography, fluoroscopy and computed tomography, a final report of coordinated research projects in Africa, Asia and Eastern Europe, IAEA-TECDOC-1423, Vienna

[9] IAEA (2007). Dosimetry in diagnostic radiology, International Code of Practice, IAEA technical report series 457, Vienna.

[10] Johnson D.A and Brennan P.C (2000). Reference dose levels for patients undergoing common diagnostic X-ray examination in Irish hospitals. British Journal of Radiology, 73 396-402

[11] Martin, C. J (2006). The importance of radiation quality for optimization in radiology, Biomedical Imaging and Intervention Journal, 3 (2) 1-14

[12] Milatovic, A, Ciraj-Bjelac, O, Ivanovic, S. Jovanovic, S and Spasic- Jokic, V (2011). Patient dose measurements in diagnostic radiology procedures in Montenegro, Radiation Protection Dosimetry, 1-10

[13] Miralbell, R. Doriat, P. A. and Nouet, P (2000). X-ray dose to skin in patients undergoing percutaneous transluminal coronary, Angioplast Catheter Cardiovascular Intervention

[14] NNRA(2003). Nigerian basic ionizing radiation regulations, Federal Government Press, Lagos, Nigeria. 
74 Essien Imeh Edet and Inyang Samuel Okon: A Survey of Radiation Exposure Techniques Factors Used for Common Diagnostics $\mathrm{X}$ - Ray Examinations in Akwa Ibom State, Nigeria

[15] NNRA (2006). Nigeria radiation safety in diagnostic and interventional radiology regulations, Federal Government Press, Lagos, Nigeria

[16] Nyathi, T, Nethwadzi, L. C. Mabhengu, T, Pule, M. L and Merwe, D. G (2009). Patient dose audit for patient undergoing six common radiography examinations: Potential dose reference levels, South African Radiography, 9-13,

[17] Olowookere, C. J. Obed, R. I. Babalola, I. A and Bello, T. O (2011). Patient dosimetry during chest, abdomen, skull and neck radiography in South West Nigeria. Radiography, 245-249

[18] Osibote, O. A. and Azevedo, A.C.P (2008). Estimation of adult patient doses for common diagnostic x-ray examinations in Rio de Janerio, Brazil; Physica Medica, 21-28

[19] UNSCEAR (2008). United Nations Scientific Committee on the Effects of Atomic Radiation, 2006 report on effects of ionizing radiation. United Nations, New York.

[20] Vano, E (2003). Radiation exposure to cardiologist, how it could be reduced, Heart, 89, 123-4

[21] Vano, E. Gonzalaz, L. Beneytez, F. and Morem, F (1998). Lens injuries induced by exposures in non- optimized interventional radiology laboratories, British Journal of Radiology 71, 728-3 